\title{
Disturbances of the body schema in relation to language impairment and hemispheric locus of lesion
}

\author{
J. SAUGUET, A. L. BENTON, AND H. HÉCAEN \\ From the Centre Neurochirurgical Sainte-Anne, Paris, France, and the Neurosensory Center and the Department \\ of Neurology, University of Iowa College of Medicine, Iowa City, U.S.A.
}

SUMMARY The relationship of disturbances of the body schema to hemispheric locus of lesion $\overrightarrow{\vec{\omega}}$ and sensory aphasic disorder was assessed by giving verbal and non-verbal tests of right-left orienta- $\omega$ tion, finger recognition, and autotopagnosis to patients with unilateral cerebral disease. The study was restricted to right-handed patients who were free from general mental impairment or confusion. The tests were also given to a group of control patients whose performances defined the range of $\stackrel{\omega}{A}$ normal performance in each test. A significant proportion of patients with sensory aphasic disordev ${ }^{\circ}$ performed defectively on all the tests, non-verbal as well as verbal, the relative frequency of failue in this group ranging from 10 to $67 \%$ for the different tests. There were, however, a number of 0 patients with sensory aphasic disorder who performed adequately on most of the tests. Defecti次 performance on the part of non-aphasic patients with lesions of either the left or the right hemisphe was quite rare in the case of 19 of the 20 tests. The exceptional test was the task of imitating later movements from Head's battery, on which both non-aphasic groups performed relatively poorl延 The patients with lesions of the right hemisphere were significantly inferior to those with left hemos. $\vec{\sigma}$ sphere disease on this test. The findings are interpreted as indicating that sensory aphasic disorder is a necessary but not sufficient condition for the occurrence of some types of bilateral 'body schema' disturbance in patients with unilateral disease. It is postulated that the sufficient condition is a combination of aphasic disorder with somatosensory impairment. Bilateral impairment of the 'body schema' does not appear to have a differential relationship to hemispheric locus of lesion perse.

Although the Gerstmann syndrome (finger agnosia, right-left disorientation, acalculia, agraphia) is viewed as a symptom of disease of the posterior area of the dominant hemisphere and its association with aphasic disorders has often been remarked, its relationship to disturbances of language generally has not been considered to be of great significance. Gerstmann $(1924,1927,1930)$ thought of the syndrome as being of a somatognosic nature-that is, as reflecting a disturbance in the body schema. Other conceptions which have been advanced are that the basic deficit is of an apraxic character (Herrmann and Pötzl, 1926), that an impairment in the appreciation of spatial relations is the common denominator (Lange, 1933; Janota, 1938; Stengel, 1944) and that the syndrome is an expression of a loss of the general capacity to apprehend part-whole relationships (Conrad, 1932).

The reality of the Gerstmann syndrome was called into question by Benton $(1959,1961)$ who pointed out that its several elements did not show closer associative bonds among themselves than they did with other 'parietal' performances such as constructional praxis, reading, and visual memory. At the

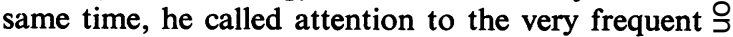
association of finger agnosia and right-left orienta- $\rightarrow$ tion with impairment in language comprehension and further pointed out that impairment in the $N$ naming of fingers was the most frequently mentioned performance deficit in 'finger agnosia'. He therefore $N$ considered the relationship between finger agnosia $\tilde{\omega}$ and left parietal lobe disease as being an indirect one 
and expressed the opinion that it is only through the mechanism of a language deficit that impairment in finger recognition is specifically associated with lesions of the dominant hemisphere.

This view that finger agnosia is an expression of a disability which is primarily of a linguistic-conceptual nature was criticized by Kinsbourne and Warrington (1962) who emphasized the distinctive character of the Gerstmann syndrome and who believed that faulty localization of the fingers was a specific impairment in the apprehension of the spatial relations among them. Ettlinger (1963) also concluded that at least one form of finger agnosia was of this nature. On the other hand, Poeck and Orgass (1966) and Orgass and Poeck (1968) have presented findings that support Benton's views. The results of their most recent study (Poeck and Orgass, 1969) indicate that verbal and non-verbal tasks involving finger recognition are essentially independent of each other; failure in verbal identification is related to aphasic disorder, while failure in non-verbal identification is associated with a number of factors, most notably mental deterioration.

The principal aim of the present study was to investigate the relations between impairment in receptive language and various disturbances of the body schema which have been attributed to disease of the dominant hemisphere. We assessed not only right-left disorientation and finger agnosia but also autotopagnosia-that is, difficulty in recognizing and naming various parts of the body. Each ability was defined in terms of the performances of the patients on a series of tests, some of which were of a verbal nature and others of which were of as nonverbal a character as possible. In addition, the patients were given the Wechsler Adult Intelligence Scale (WAIS); those whose IQ score was below 80 were classified as mentally deteriorated. Brief tests of temporal and spatial orientation were also given and those patients who performed inadequately were classified as confused.

Giving these tests to groups of patients with unilateral cerebral disease provided the possibility of: (1) assessing the degree of association between impairment in receptive language and performance on verbal and non-verbal tasks involving recognition of parts of the body; (2) determining whether or not different disturbances in body recognition show the same relationship to impairment in receptive language; (3) assessing the relationship between body schema disturbances and hemispheric locus of lesion, independently of the status of receptive language; (4) determining whether disturbances in body recognition would be disclosed in the absence of both sensory aphasia (as indicated by normal performance on tests of comprehension and naming) and mental deterioration or confusion (as indicated by an IQ of at least 80 and adequate temporal and spatial orientation).

\section{METHOD}

The examination procedures involved assessment of: (1) right-left orientation; (2) finger recognition; (3) autotopagnosis; (4) recognition of object-parts with names corresponding to parts of the body-for example, 'arm' of a chair; (5) recognition of parts of the bodies of animals.

With the exception of the test for finger naming, all the tests were so designed as to minimize as much as possible the occurrence of errors which might result from disturbances in naming. At the same time, it was possible to demonstrate through gesture the type of response required to patients with difficulties in oral understanding. Each subject was assessed individually, the examiner sitting in front of him and presenting the series of tests listed below.

The tests are grouped in the form in which the results were analysed and not in the order in which they were given, which was dictated by considerations of ease of administration.

1. RIGHT-LEFT ORIENTATION: ONE'S OWN BODY (16 responses) On verbal command, the patient pointed to his right arm, left ear, etc. (six responses) and executed the head-eye-ear movements from Head's test (10 responses). Only errors of a lateral nature were scored on this and the other tests of right-left orientation.

2. RIGHT-LEFT ORIENTATION: CONFRONTING EXAMINER AND FRONT-VIEW MODEL (12 responses) On verbal command, the patient pointed to the right arm, left ear, etc., of the confronting examiner (six responses) and to the same body parts on a front-view model of the human body (six responses).

3. RIGHT-LEFT ORIENTATION: BACK OF EXAMINER AND OF MODEL (12 responses) On verbal command, the patient pointed to the right arm, left ear, etc., of the examiner when his back was turned (six responses) and on a rearview model of the human body (six responses).

4. RIGHT-LEFT ORIENTATION: IMITATION (nine responses) The patient imitated the head-eye-ear movements from Head's test.

5. RIGHT-LEFT ORIENTATION: OBJECTS ( 10 responses) This test utilized four objects (ashtray, match box, key, pencil) and required the patient to place one to the right or left of another (five responses) or to point to the object at the right or left of another (five responses).

6. FINGER RECOGNITION: NAMING (10 responses) The patient was instructed to name the fingers touched by the examiner, first with the aid of vision (five responses) and then with eyes closed (five responses).

7. FINGER RECOGNITION: IDENTIFICATION BY NAME $(30$ responses) The patient pointed to the finger named by the examiner on each of his own hands (10 responses), on each of the examiner's hands (10 responses), and on a schematic model of each hand (10 responses).

8. FINGER RECOGNITION: IDENTIFICATION BY NUMBER ( 30 responses) The patient pointed to the finger which the 
examiner had designated by number on each of his own hands (10 responses), on each of the examiner's hands (10 responses), and on schematic models of the hands (10 responses).

9. IMITATION AND IDENTIFICATION OF FINGER MOVEMENTS (15 responses) The patient was instructed to imitate finger movements made by the examiner (five responses); with the aid of vision, to indicate on a schematic model of the hand which of his fingers had been touched by the examiner (five responses); having closed his eyes while each finger was touched, to open his eyes and indicate on the schematic model which finger had been touched (five responses).

10. INTERDIGITAL OBJECT IDENTIFICATION (eight responses) Following the procedure of Kinsbourne and Warrington (1962), an object was placed between two fingers of the patient whose eyes were closed and who was then required to indicate which fingers were involved. The choice of response was left to the patient who could indicate the fingers by name or number or by pointing to them on a model of the hand, thus eliminating the necessity of verbal responses.

11. AUTOTOPOGNOSIs: OWN BODY (14 responses) The patient was instructed to point to the part of his body named by the examiner.

12. AUTOTOPOGNOSIS: EXAMINER'S BODY (11 responses) The patient was instructed to point to the part of the examiner's body named by him.

13. AUTOTOPOGNOSIS: DRAWING OF BODY (11 responses) The patient was instructed to point to body parts on a drawing of the body named by the examiner.

14. AUTOTOPOGNOSIS: IMITATION (nine responses) The subject was instructed to imitate the movements of the examiner touching different parts of his own body; mirror-image responses were not counted as errors.

15. RECOGNITION OF PARTS OF OBJECTS (six responses) Parts of objects with names corresponding to parts of the body-for example, teeth of a comb, leg of a table, head of a pin-were named by the examiner and the patient was instructed to point to them.

16. RECOGNITION OF ANIMAL PARTS (seven responses) presented with a picture of an elephant, the patient was instructed to point to various body parts-for example, foot, tusk, trunk-named by the examiner.

\section{SUBJECTS}

The subjects of the study comprised 80 patients with unilateral lesions who were drawn from a larger sample of 108 patients, all of whom had been given the battery of tests. Left-handed patients (10 cases) and those who exhibited mental deterioration or confusion (14 cases) were subsequently excluded, leaving 31 patients with lesions of the right hemisphere and 49 patients with lesions of the left hemisphere. The mean ages of the two samples were 45.8 years and 47.6 years, respectively. Seventy-one per cent of the patients with right hemisphere disease and $59 \%$ of those with left hemisphere disease had an educational level corresponding to, or higher than the certificat d'études primaires-that is, successful completion of eight or more years of study. Tumour (surgically verified in all instances) was the most frequent diagnosis in both samples $(55 \%$ in the right hemisphere sample, $35 \%$ in the left hemisphere sample) and cerebrovascular disease was the next most frequent diagnosis (23\% in the right hemisphere sample, $33 \%$ in the left hemisphere sample). So far as could be determined from surgical, radiographic, and clinical findings, there was no tendency for the left hemisphere aphasic group to have larger lesions than the other two groups.

All patients in the right hemisphere sample (designated as the RH group) showed adequate receptive and expressive language capacity, as assessed by tests of comprehension and naming. In the LH sample, 28 patients showed no deficits in oral language comprehension or in naming, although some showed motor speech impairment. These were designated as the LH-NA groupthat is, without sensory aphasia. The remaining 21 patients in the left hemisphere sample showed deficits in oral language understanding together with disturbances in naming and were designated as the LH-A groupthat is, with sensory aphasia.

A control group of 20 right-handed patients without history or evidence of cerebral disease was also given the battery of tests. Their mean age was 41.5 years and $85 \%$ of the group had an educational level corresponding to, or higher than, the certificat d'études primaires.

\section{RESULTS}

All 20 control patients made errorless performance on the test battery, an outcome that was perhaps correlated with their relatively high intellectua level. However, $18(58 \%)$ of the 28 patients witk right hemisphere lesions and $20(71 \%)$ of the 28 non-aphasic patients with left hemisphere disease also made errorless performances on the entire test battery, indicating that, even in these groups, perfect performance was the rule rather than the exception. On the other hand, only two $(10 \%)$ of the patients in the LH-A group made errorless performances on the test battery. On the basis of these observations, the occurrence of two or more errors on a test was adopted as a criterion of defective performance on that test.

The proportions of patients in each group $(\mathrm{RH}$, LH-NA, LH-A) performing adequately on each test -that is, making not more than one error-is shown in Table 1. A striking contrast between the aphasic group and the two non-aphasic groups is immediately evident. While the non-aphasic groups performed adequately on most of the tests, the aphasic group was defective on every test.

The intergroup differences in the proportion of patients performing adequately on each test were evaluated statistically by a set of specific contrasts employing the Mann-Whitney U-Test which assesses the significance of the difference between two distributions of scores. The LH-A group was inferior to the LH-NA group on every test, 19 of 
T A B L E 1

PROPORTIONS OF PATIENTS WITH NORMAL PERFORMANCES

\begin{tabular}{|c|c|c|c|}
\hline \multirow[t]{2}{*}{ Test } & \multicolumn{3}{|c|}{ Groups } \\
\hline & $\begin{array}{c}R H \\
(N=3 I) \\
(\%)\end{array}$ & $\begin{array}{c}L H-N A \\
(N=28) \\
(\%)\end{array}$ & $\begin{array}{c}L H-A \\
(N=2 I) \\
(\%)\end{array}$ \\
\hline $\begin{array}{l}\text { 1. Right-Left Orientation: } \\
\text { One's Own Body }\end{array}$ & 97 & 96 & 29 \\
\hline $\begin{array}{l}\text { 2. Right-Left Orientation: Con- } \\
\text { fronting Examiner and }\end{array}$ & & & \\
\hline $\begin{array}{l}\text { Front-View Model } \\
\text { 3. Right-Left Orientation: Back of }\end{array}$ & 84 & 96 & 43 \\
\hline Examiner and Model & 94 & 93 & 52 \\
\hline 4. Right-Left Orientation: Imitation & 61 & 79 & 52 \\
\hline 5. Right-Left Orientation: Objects & 94 & 93 & 43 \\
\hline $\begin{array}{l}\text { 6. Finger Recognition: Naming } \\
\text { 7. Finger Recognition: Identifi- }\end{array}$ & 77 & 75 & 19 \\
\hline $\begin{array}{l}\text { cation by Name } \\
\text { 8. Finger Recognition: Identifi- }\end{array}$ & 87 & 86 & 19 \\
\hline $\begin{array}{l}\text { cation by Number } \\
\text { 9. Imitation and Identification of }\end{array}$ & 100 & 100 & 52 \\
\hline Finger Movements & 97 & 100 & 81 \\
\hline 10. Interdigital Object Identification & 97 & 96 & 62 \\
\hline $\begin{array}{l}\text { 11. Autotopognosis: Own Body } \\
\text { 12. Autotopognosis: Examiner's }\end{array}$ & 100 & 100 & 71 \\
\hline $\begin{array}{l}\text { Body } \\
\text { 13. Autotopognosis: Drawirg of }\end{array}$ & 100 & 100 & 62 \\
\hline Body & 100 & 100 & 57 \\
\hline 14. Autotopognosis: Imitation & 100 & 100 & 90 \\
\hline 15. Recognition of Parts of Objects & 100 & 100 & 71 \\
\hline 16. Recognition of Animal Parts & 100 & 100 & 86 \\
\hline
\end{tabular}

RH = Patients with lesions of the right hemisphere; LH-NA = Patients with lesions of the left hemisphere and without sensory aphasia. LH-A = Patients with lesions of the left hemisphere and with sensory aphasia.

the 20 differences being significant at the 0.01 confidence level and the remaining difference (test 14Autotopognosis: Imitation) being significant at the 0.05 level. The LH-A group was significantly inferior to the RH group on 19 of the 20 tests, the exception being test 4 (Right-Left Orientation: Imitation) on which both groups performed poorly. The LH-NA and RH groups did not differ significantly in performance on 19 of the 20 tests, the exception again being test 4 . On this test requiring imitation of the examiner's movements, the RH group was inferior to the LH-NA group.

The two tests on which the LH-NA and RH groups showed an impressive frequency of failure were Right-Left Orientation: Imitation (test 4) and Finger Recognition: Naming (test 6). As might be expected, finger naming was also particularly difficult for the aphasic patients, only four of the 21 patients in this group performing adequately. On the other hand, imitation of lateral movements of the examiner was not a distinctively difficult task for them, 11 of the 21 aphasic patients performing on a satisfactory level. Nevertheless, even on this task the aphasic patients were significantly inferior to the non-aphasic patients with left hemisphere disease.

A second analysis dealing with the relative frequency of severely defective performances in the three groups of patients was also done. For this purpose, 'severe' defect was defined as the occurrence of three or more errors on tests with six to eight items (tests 10,15,16), four or more errors on tests with nine to 16 items (tests $1-6,9,11-14$ ), and six or more errors on tests with 30 items (tests 7,8 ). The findings are presented in Table 2, which shows the proportion of patients in each group who performed defectively on each test. Inspection of Table 2 supports the following generalizations:

1. Defective performance is far more frequent in the LH-A group than in the RH or LH-NA groups; however, substantial numbers of patients with sensory aphasia do not show severe defect on the tasks;

2. A relatively small proportion of non-aphasic patients show severe defect on some tasks such as right-left orientation on the examiner or a schematic

T A B L E 2

PROPORTIONS OF PATIENTS SHOWING SEVERE PERFORMANCE DEFICITS

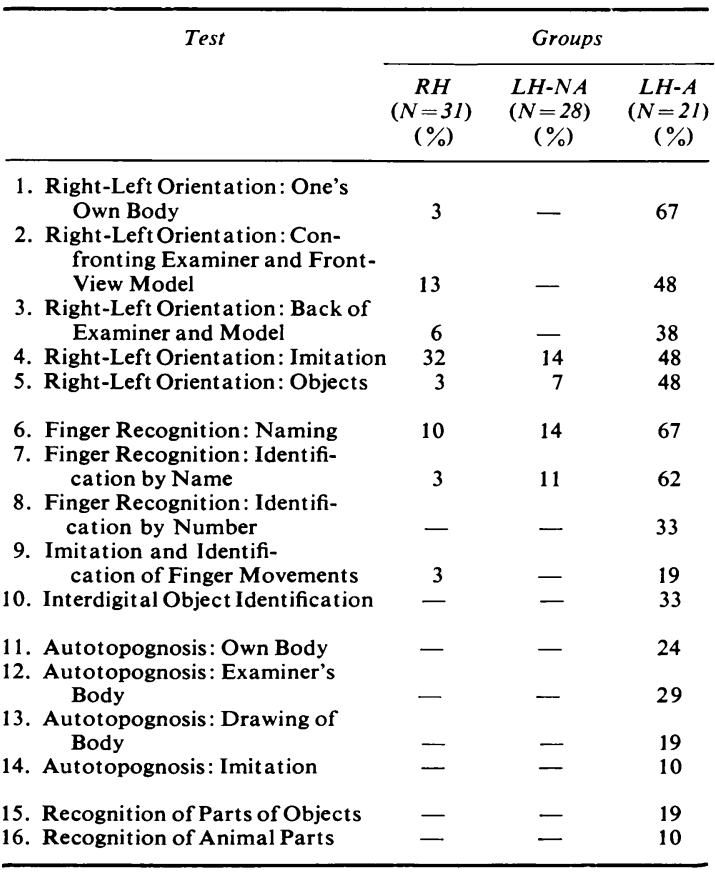

RH = Patients with lesions of the right hemisphere. LH-NA = Patients with lesions of the left hemisphere and without sensory aphasia. LH-A = Patients with lesions of the left hemisphere and with sensory aphasia. 
model, imitation of lateral movements and finger naming;

3. Defective performance is shown with about equal frequency by non-aphasic patients with lesions of the right or left hemisphere.

\section{DISCUSSION}

The results are clear in their indications that disturbances of the body schema are closely related to impairment of language comprehension in patients with unilateral cerebral disease. Since impairment in language understanding is generally associated with disease of the left hemisphere, body schema disturbances are more likely to be observed in patients with lesions of that hemisphere than in those with right hemisphere disease. However, that there is no essential relationship between the occurrence of these somatognosic defects and hemispheric locus of lesion is shown by the finding that, when receptive language impairment is excluded from consideration, patients with left hemisphere disease did not show a higher frequency of deficit than did those with right hemisphere disease.

Patients with receptive language impairment generally showed poorer performance on verbal body schema tasks-for example, finger naming, identification of fingers by name - than on tasks that do not require either a verbal response or comprehension of a name-for example, imitation and identification of finger movements, interdigital object identification. In this regard, it is interesting to note that the aphasic patients performed on a decidedly higher level in localizing fingers that the examiner identifies by number than those that he identifies by name. However, as the Tables show, their overall performance on the identification by number task was still quite defective.

While the aphasic patients showed a very high incidence of defect on the body schema tasks, even on those of a non-verbal nature, a significant number of them did not show widespread impairment and, as has been mentioned, two of them performed perfectly on all 16 tests. Thus it appears that, although receptive language impairment is closely related to failure on somatognosic tasks, it is not in itself a sufficient condition for such failure. On the other hand, this close relationship and the fact that defective performance was shown by only a very few non-aphasic patients suggests that receptive language impairment is practically a necessary condition for the appearance of significant disturbance in finger recognition or right-left disorientation in patients who are not mentally deteriorated or confused.

Conceivably, aphasic disorder interacts with another factor to produce defects in these cognitive areas. This view was proposed by Benton (1959) who ascribed the occurrence of finger agnosia and rightleft disorientation in patients with disease of the dominant hemisphere 'to a combination of a disturbance of the body schema with an impairment in symbolic comprehension'. More recently, in an effort to account for the fact that some (but not all) aphasic patients show notable impairment in finger recognition as well as particular difficulty in understanding and giving the names of the body parts as compared to their efficiency in understanding and giving the names of other objects, Selecki and Herron (1965) have advanced the concept that disturbances of the 'verbal body image' represent a particular syndrome of sensory aphasia. They consider the syndrome as one of a number which may result from disease of the parieto-temporal-occipital area of the dominant hemisphere and see it as representing the outcome of sensory aphasic disorder combined with somatosensory impairment.

The one test on which a substantial number of non-aphasic patients performed poorly was the imitation task taken from Head's battery. It is noteworthy that on this test the $\mathrm{RH}$ group was. significantly inferior to the LH-NA group, theif performance being on a level which was not greatlyD different from that of the aphasic patients. It is pos sible that a specific spatial factor is involved in the execution of this task and that those patients witlo right hemisphere disease who failed the test suffered from visuoperceptive disabilities. An empi을 rical test of the tenability of this hypothesis is planned.

Left-handed patients and those showing general mental impairment or confusion were excluded from the study so that the influence of hemispheric locus of lesion and of receptive language disorder could be evaluated independently of these more general factors. Inspection of the performances of the relatively few left-handed patients examined suggests that handedness is significantly related to performance on these body schema tasks, left-handed control patients and non-aphasic patients with cerebral lesions making more errors than their right-handed counterparts. A detailed analysis of this question is planned as a sufficient number of left-handed cases in each diagnostic group becomes available.

The mentally impaired and confused patients generally performed poorly, their level being comparable with that of the patients with receptive language disorder. Thus our findings support the conclusion of Poeck and Orgass (1969) that mental deterioration is an important determinant of observed deficits in finger recognition and right.-left orientation in non-aphasic patients. 
This investigation was supported by grants from the Centre National de la Rechèrche Scientifique, INSERM, and the Foundations' Fund for Research in Psychiatry (Dr. Hécaen) and Grants NS-00616 and NS-03354 from the National Institute for Neurological Diseases and Stroke (Dr. Benton).

\section{REFERENCES}

Benton, A. L. (1959). Right-left Discrimination and Finger Localization: development and pathology. Hoeber: New York.

Benton, A. L. (1961). The fiction of the 'Gerstmann syndrome'. J. Neurol. Neurosurg. Psychiat., 24, 176-181.

Conrad, K. (1932). Versuch einer psychologischen Analyse des Parietalsyndroms. Mschr. Psychiat. Neurol., 84, 28-97.

Ettlinger, G. (1963). Defective identification of fingers. Neuropsychologia, 1, 39-45.

Gerstmann, J. (1924). Fingeragnosie. Eine umscriebene Störung der Orientierrung am eigenen Körper. Wien. klin. Wschr., 37, 1010-1012.

Gerstinann, J. (1927). Fingeragnosie und isolierte Agraphie, ein neues Syndrom. Z. ges. Neurol. Psychiat., 108, 152-177.
Gerstmann, J. (1930). Zur Symptomatologie - der Hirnläsionen im Uebergangsgebiet der unteren Parietal- und mittleren Occipitalwindung. Nervenarzt, 3, 691-695.

Herrmann, G., and Pötzl, O. (1926). Uber die Agraphie und ihre lokaldiagnostischen Beziehungen. Abhandl. Neurol. Psychiat. Psychol. Heft 35, Karger: Berlin.

Janota, O. (1938). Sur l'apraxie constructive et sur les troubles apparentés de l'aperception et de l'expression des rapports spatiaux. Encéphale, 2, 173-211.

Kinsbourne, M., and Warrington, E. K. (1962). A study of finger agnosia. Brain, 85, 47-66.

Lange, J. (1933). Probleme der Fingeragnosie. Z. ges. Neurol. Psychiat., 147, 594-610.

Orgass, B., and Poeck, K. (1968). Recht-Links-Störung oder Aphasie? Dtsch. Z. Nervenheilk., 194, 261-279.

Poeck, K., and Orgass, B. (1966). Gerstmann's syndrome and aphasia. Cortex, 2, 421-437.

Poeck, K., and Orgass, B. (1969). An experimental investigation of finger agnosia. Neurology (Minneap.), 19, 801-807.

Selecki, B. R., and Herron, J. T. (1965). Disturbances of the verbal body image: a particular syndrome of sensory aphasia. J. nerv. ment. Dis., 141, 42-52.

Stengel, E. (1944). Loss of spatial orientation, constructional apraxia and Gerstmann's syndrome. J. ment. Sci., 90, 753-760. 